\title{
Pancreatic cancer: gradual rise, increasing relevance
}

\section{Pancreatic cancer is likely to become one of the leading causes of cancer death in Australia}

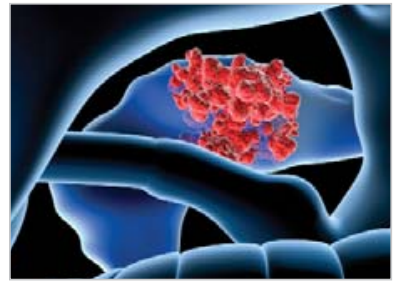

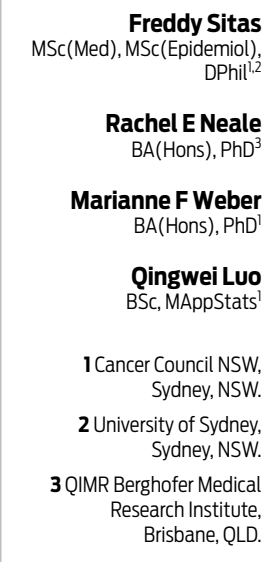

freddy.sitas@gmail.com

doi: 10.5694/mjal5.00137 sidered causal ${ }^{4}$ with local published data suggesting a lag of about 30 years between smoking trends and incidence. ${ }^{5}$ However, overweight and obesity may also have contributed, in part, to incidence trends. ${ }^{6}$

In Australia (and other developed countries), only about $50 \%-70 \%$ of cases of pancreatic cancer are histologically confirmed based on review of the primary tumour, ${ }^{1}$ because pancreatic biopsy procedures have been associated with significant risks ${ }^{7}$ and are often avoided. But improvements in imaging modalities, particularly endoscopic ultrasound and pancreas-specific computed tomography, and magnetic resonance imaging protocols, together with endoscopically guided biopsy procedures, are likely to have led to some of the increase in incidence through improved detection.

\section{Survival and mortality}

In 2011, the latest year for which results are available, 5 -year survival from pancreatic cancer was $5.2 \%$ in Australia and $7.3 \%$ in the United States (among patients on selected Surveillance, Epidemiology and End Results Program registers) with only modest improvements observed over the past several decades. Five-year survival from pancreatic cancer was about $3 \%$ in the mid 1980s in

both places. ${ }^{89}$ Between 1987 and 2007 in Australia there was only a $6 \%$ drop in mortality from pancreatic cancer in both sexes (in those aged less than 75 years), compared with decreases in mortality of $34 \%$ from lung cancer, $47 \%$ from bowel cancer and $28 \%$ from all cancers overall. ${ }^{10}$ Current projections suggest that within 10 years, pancreatic cancer will be the second-highest cause of cancer death in the US as mortality and survival from the other four leading causes of cancer death (lung, bowel, prostate, and breast cancers) improves. ${ }^{11}$ If these trends are reflected

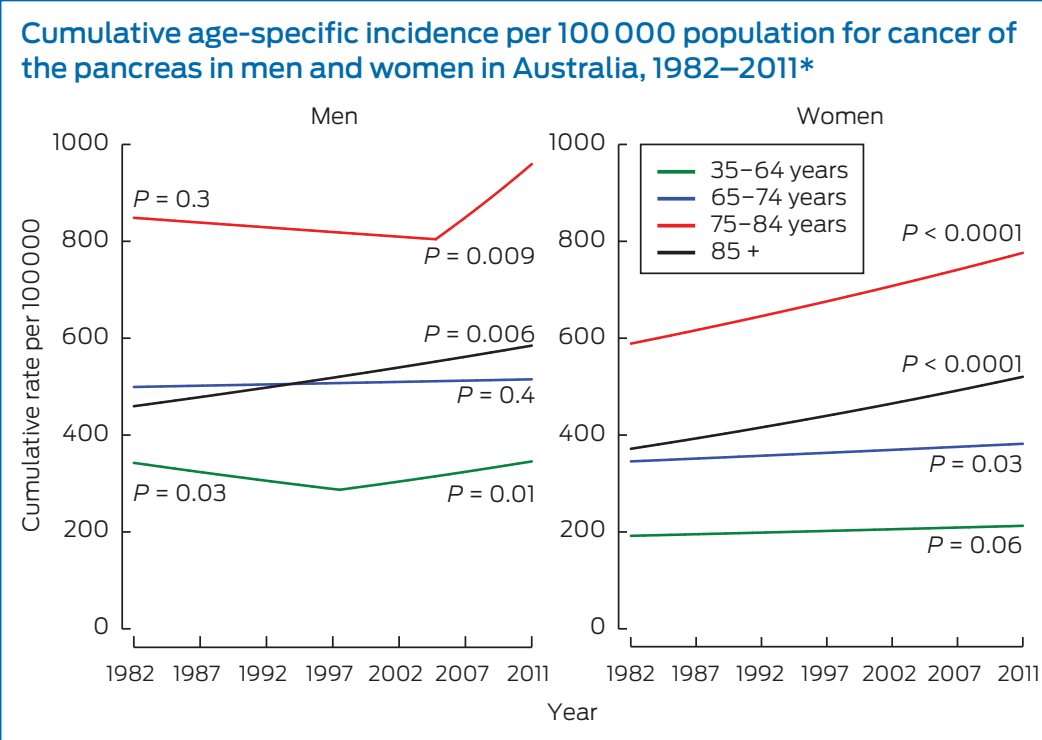

*P values are shown for the slope of trend, with joinpoint regression analysis used to identify points where this slope changed significantly. ${ }^{2}$

Data source: Australian cancer incidence and mortality (ACIM) books. ${ }^{3}$ 
Complete resection of

the primary

tumour

currently

offers the

only hope

of cure in Australia, we would anticipate that pancreatic cancer will become one of the leading causes of cancer mortality.

Complete resection of the primary tumour currently offers the only hope of cure. While 5-year survival in those who have local or regional involvement remains low, at $15 \%-20 \%$, it is significantly better than the 5 -year survival of $3 \%$ in people with metastatic disease. Thus, increasing the proportion of patients diagnosed with resectable disease from the currently dismal $15 \%$ seen in Queensland and New South Wales ${ }^{12}$ by diagnosing the disease earlier may be beneficial. However, beyond the setting of high-risk families, screening to identify precursor or early invasive lesions is not feasible for two main reasons. First, endoscopic ultrasound is invasive and can only be used in specialised settings, so does not meet criteria for a population screening test. Molecularbased screening may become available in the future, at least partially overcoming this problem. Second, the positive predictive value of screening is limited by the low population prevalence of pancreatic cancer. Attempts to stratify the population using known risk factors, including several known single nucleotide polymorphisms, have not yet identified population subgroups at sufficiently high risk to warrant screening. ${ }^{13}$

\section{Optimising outcomes}

An avenue to optimise outcomes for patients is to ensure that all receive high-quality care in the most appropriate setting. There is evidence from the US that not all patients with potentially resectable tumours are offered surgery. ${ }^{14}$ Detailed data are not currently available for Australia, but it appears that there is similar underutilisation of surgery here. ${ }^{12,14,15}$ It is thus important that all patients without metastatic disease are reviewed by a multidisciplinary team in a major centre to determine the resectability of their pancreatic tumours. In addition, resections should be performed in hospitals that carry out a large number of these procedures annually, as this has been shown to improve survival. ${ }^{16}$

Investment in research to identify cure, beyond surgery, has increased in the past decade. Sequencing of tumour tissue to identify tumour-specific genetic profiles offers the possibility of tailored treatment, with the hope that this will improve survival and avoid unnecessary side effects. In a whole-genome sequencing study of 100 patients with pancreatic cancer, four subtypes with potential clinical utility were identified, and in a subgroup of eight patients receiving platinum-based therapy, four out of five with the "on-genotypes" had exceptional or partial responses, while three patients who did not have these genotypes did not respond. ${ }^{17}$ Other promising approaches, such as targeting tumours with immunotherapy, are also being explored..$^{18}$

In conclusion, while the rise in pancreatic cancer incidence in Australia is only slow, as the population ages, more people will be affected with this devastating disease. The burden of pancreatic cancer relative to other cancer types is likely to increase. A multilevel approach is needed to control pancreatic cancer, including reducing the prevalence of risk factors such as smoking and obesity, identifying effective biomarker screening tools and populations in whom screening or early detection might be feasible, discovering new treatment modalities and ensuring that all patients have access to optimal care.

Acknowledgements: Rachel Neale is funded by a National Health and Medical Research Council fellowship (1060183).

Competing interests: No relevant disclosures.

Provenance: Commissioned; externally peer reviewed.

References are available online at www.mja.com.au. 
1 Forman D, Bray F, Brewster DH, et al. Cancer incidence in five continents. Vol. X (electronic version). Lyon: International Agency for Research on Cancer, 2013. http://ci5.iarc.fr/Cl5-X/ Default.aspx (accessed Feb 2015).

$2 \mathrm{Kim} \mathrm{HJ}$, Fay MP, Feuer EJ, et al. Permutation tests for joinpoint regression with applications to cancer rates. Stat Med 2000; 19: 335-351.

3 Australian Institute of Health and Welfare. Australian cancer incidence and mortality (ACIM) books. Australian Institute of Health and Welfare, Canberra. http://www.aihw.gov.au/acimbooks (accessed Feb 2015).

4 Secretan B, Straif K, Baan R, et al. WHO International Agency for Research on Cancer Monograph Working Group. A review of human carcinogens - Part E: tobacco, areca nut, alcohol, coal smoke, and salted fish. Lancet Oncol 2009; 10: 1033-1034.

5 Adair T, Hoy D, Dettrick Z, et al. Tobacco consumption and pancreatic cancer mortality: what can we conclude from historical data in Australia? Eur J Public Health 2012; 22 : 243-247.

6 World Cancer Research Fund. Food, nutrition, physical activity and the prevention of cancer: a global perspective. Washington, DC: American Institute for Cancer Research, 2007.

76 Clarke DL, Clarke BA, Thomson SR, et al. The role of preoperative biopsy in pancreatic cancer. HPB (Oxford) 2004; 6: 144-153.

8 Australian Institute of Health and Welfare. Cancer survival and prevalence in Australia: period estimates from 1982 to 2010. Canberra: AlHW, 2012. (AlHW Cat. No. CAN65.) http://www. aihw.gov.au/publication-detail/?id=10737422720 (accessed Apr 2015).

9 Howlader N, Noon AM, Krapcho M, et al. SEER cancer statistics review, 1975-2011. (Based on November 2013 SEER data submission, posted to the SEER webiste, April 2014.) http:// seer.cancer.gov/csr/1975_2011 (accessed Feb 2015).

10 Sitas F, Gibberd A, Kahn C, et al. Cancer incidence and mortality in people aged less than 75 years: changes in Australia over the period 1987-2007. Cancer Epidemiol 2013; 37: 780-787.

11 Rahib L, Smith BD, Aizenberg R, et al. Projecting cancer incidence and deaths to 2030: the unexpected burden of thyroid, liver, and pancreas cancers in the United States. Cancer Res 2014; 74: 2913-2921.

12 Burmeister EA, O'Connell DL, Beesley VL, et al. Describing patterns of care in pancreatic cancer - a population-based study. Pancreas 2015. In press.

13 Klein AP, Lindstrom S, Mendelsohn JB, et al. An absolute risk model to identify individuals at elevated risk for pancreatic cancer in the general population. PLOS One 2013; 8: e72311.

14 Bilimoria KY, Bentrem DJ, Ko CY, et al. National failure to operate on early stage pancreatic cancer. Ann Surg 2007; 246: $173-180$.

15 Chang DK, Merrett ND, Biankin AV. Improving outcomes for operable pancreatic cancer: is access to safer surgery the problem? J Gastroenterol Hepatol 2008; 23: 1036-1045.

16 Finks JF, Osborne NH, Birkmeyer JD. Trends in hospital volume and operative mortality for high-risk surgery. N Engl J Med 2011; 364: 2128-2137.

17 Waddell N, Pajic M, Patch AM, et al. Whole genomes redefine the mutational landscape of pancreatic cancer. Nature 2015; 518: 495-501.

18 Le DT, Wang-Gillam A, Picozzi V, et al. Safety and survival with GVAX pancreas prime and Listeria monocytogenesexpressing mesothelin (CRS-207) boost vaccines for metastatic pancreatic cancer. J Clin Oncol 2015; Jan 12. pii: JCO.2014.57.4244. [Epub ahead of print]. 